Cahiers d'études africaines

\title{
Présentation du premier numéro des Cahiers, janvier 1960
}

Fernand Braudel

\section{OpenEdition}

1 Journals

Édition électronique

URL : https://journals.openedition.org/etudesafricaines/16150

DOI : 10.4000/etudesafricaines. 16150

ISSN : 1777-5353

Éditeur

Éditions de l'EHESS

\section{Édition imprimée}

Date de publication : 20 novembre 2010

Pagination : 373-374

ISBN : 978-2-7132-2252-8

ISSN : 0008-0055

Référence électronique

Fernand Braudel, «Présentation du premier numéro des Cahiers, janvier 1960 », Cahiers d'études africaines [En ligne], 198-199-200 | 2010, mis en ligne le 02 janvier 2013, consulté le 22 avril 2022 URL : http://journals.openedition.org/etudesafricaines/16150; DOI : https://doi.org/10.4000/ etudesafricaines. 16150

Ce document a été généré automatiquement le 22 avril 2022.

(c) Cahiers d'Études africaines 


\title{
Présentation du premier numéro des Cahiers, janvier 1960
}

\author{
Fernand Braudel
}

C'est avec le plus grand plaisir que j'écris ces quelques mots de présentation pour les Cahiers d'Études africaines à qui je souhaite longue vie et prospérité ${ }^{1}$. Ils mettent en cause l'Afrique Noire, cet univers en mouvement, aussi digne d'intérêt intellectuel que d'intérêt humain en raison des progrès accomplis et des précieux héritages conservés. Les Cahiers se proposent de préciser tout à la fois les visages anciens et les visages nouveaux du Continent Noir. Une grande expérience humaine y est en cours. Peut-être, n'ayant pour le bien comprendre qu'une vive sympathie et quelques souvenirs d'escales rapides - et non pas l'irremplaçable et multiple formation d'un " africaniste » - ai-je tendance à voir ces problèmes trop simples et trop nets. Mais j'en perçois, comme tous les spectateurs de bonne foi, la magnifique grandeur. J'écrivais, il y a quelques mois, dans l'Encyclopédie française : "Aujourd'hui il y a quelque chose de changé dans l'Afrique Noire : c'est, tout à la fois, l'intrusion des machines, la mise en place d'enseignements, la poussée de vraies villes, une moisson d'efforts passés et présents, une occidentalisation qui a fait largement brèche, bien qu'elle n'ait certes pas pénétré jusqu'aux moelles; les ethnographes amoureux de l'Afrique Noire, comme Marcel Griaule, le savent bien. Mais l'Afrique Noire est devenue consciente d'elle-même, de sa conduite, de ses possibilités. Dans quelles conditions ce passage s'opère-t-il, au prix de quelles souffrances, avec quelles joies aussi, vous le sauriez en vous y rendant. » Vous le saurez aussi en lisant nos Cahiers: «[...] Au fait, si j'avais à chercher une meilleure compréhension de ces difficiles évolutions culturelles, au lieu de prendre comme champ de bataille et d'expérience, les derniers jours de Byzance, je partirais vers l'Afrique Noire. Avec enthousiasme. " Le lecteur verra que cet enthousiasme, ce besoin de connaître, de comprendre et d'aimer anime ces Cahiers présentés avec le concours de la $\mathrm{VI}^{\mathrm{e}}$ Section de l'École pratique des hautes études. Ils réunissent dans une tâche fraternelle les africanistes français, mais aussi les africanistes du monde désireux de collaborer à une œuvre désintéressée de science et de vérité. Le programme, raison d'être de cette œuvre et de notre maison, est une fois de plus de grouper les spécialistes, de les rapprocher les uns des autres dans un effort commun de recherche. 
En Afrique Noire, comme ailleurs, la réalité humaine, dans nos images, ne prend son relief entier, qu'éclairée de tous les côtés à la fois. La géographie, l'histoire, la démographie, l'anthropologie, l'économie, l'enquête sociale seront présentes au rendez-vous. Le programme des Cahiers est une somme coordonnée de recherches, une multiplicité voulue d'éclairages. Un beau, un nécessaire programme.

\section{NOTES}

1. Nous avons tiré cet article du premier numéro des Cahiers d'Études africaines (1960, $\left.\mathrm{n}^{\circ} 1\right)$. 